\title{
Role of Emerging IoT Big Data and Cloud Computing for Real Time Application
}

\author{
Mamoona Humayun \\ College of Computer and Information Sciences \\ Jouf University, Saudi Arabia
}

\begin{abstract}
Although the Internet of things (IoT), cloud computing (CC), and Big Data (BGD) are three different approaches that have evolved independently of each other over time; however, with time, they are becoming increasingly interconnected. The convergence of IoT, CC, and BGD provides new opportunities in various real-time applications, including telecommunication, healthcare, business, education, science, and engineering. Together, these approaches are facing various challenges during data gathering, processing, and management. The focus of this research paper is to pinpoint the emerging trends in IoT, CC, and BGD. The convergence of these approaches and their impact on various real-time applications, benefits, and challenges associated with all these approaches, current industry trends, and future research directions with especial focus on the healthcare domain. The paper also provides a conceptual framework that integrates IoT, CC, and BGD and provides an IoT centric cloud infrastructure using BGD. Finally, this paper summarizes by providing directions for researchers and practitioners about how to leverage the benefits of combining these approaches.
\end{abstract}

Keywords-Internet of Things (IoT); big data (BGD); cloud computing (CC); sensors; actuators; healthcare

\section{INTRODUCTION}

IoT is a network of web-enabled devices that collect data from the surrounding environment using sensors, process it, and send it over the network. IoT has evolved in the past few decades and now became a reality in almost all real-life applications $[1,2]$. Billions of diverse devices are interconnected these days and producing a large amount of versatile data (big data). These diverse devices include sensors, actuators, home appliances, smartphones, smart devices, cars, roads, and many other objects that can be connected, actuated, or monitored, as shown in Fig. 1. These devices are not only interconnected rather also connected with the internet using heterogeneous access networks [3-5]. These abundant interconnected devices aim to provide a smart and sustainable society and the overall economy. However, these IoT devices are facing various challenges, and the most important of them is the limited computational and storage capabilities of IoT sensors that collect real-time data. The desired benefits from these IoT devices can only be achieved if these devices are attributed to the reliability, efficiency, high performance, scalability, and ubiquitous accessibility. IoT platforms usually leverage the benefits of cloud computing for storing, processing, and presentation of a huge amount of collected data [6-9].
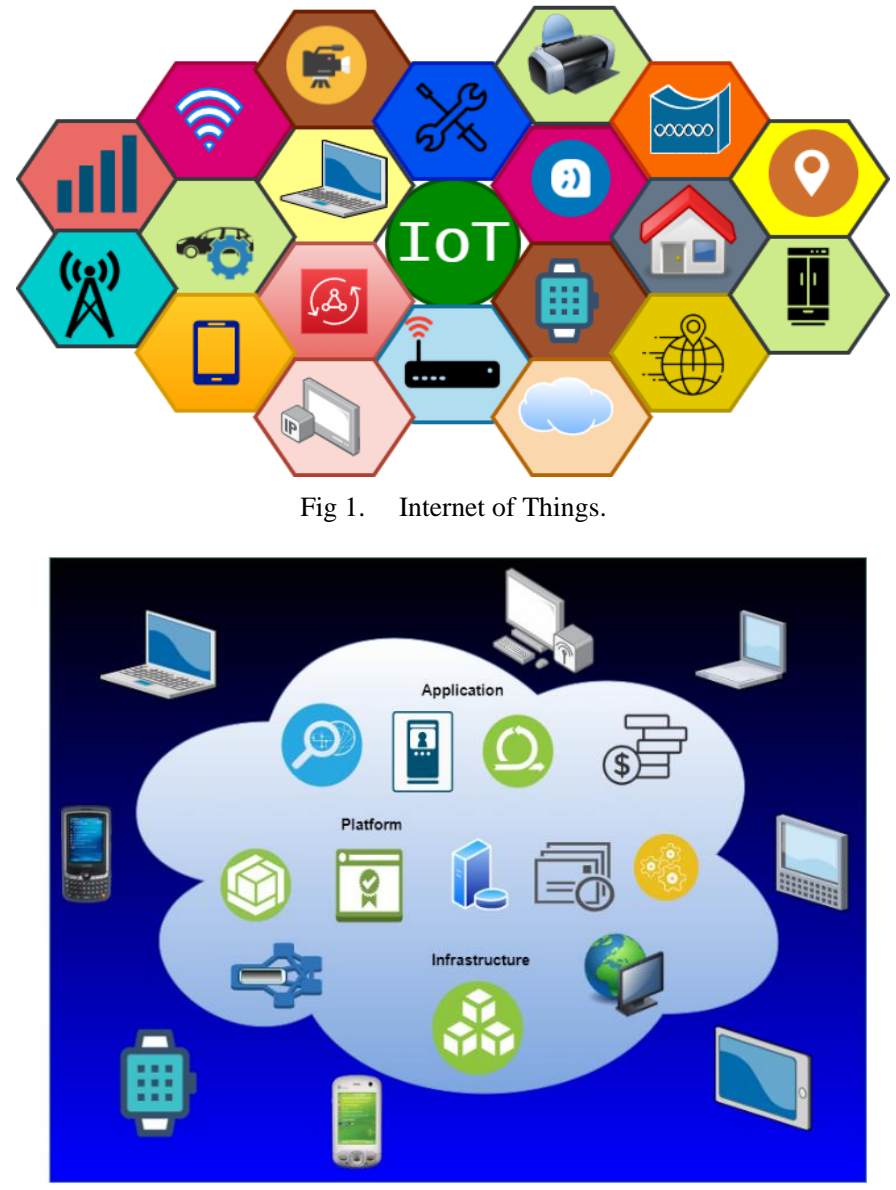

Fig 2. Cloud Infrastructure.

Cloud computing (CC) is like a data center that is ondemand available to any users over the internet. It relies on resource sharing for attaining coherency and economy of scale. Cloud may be an enterprise cloud (limited to a single organization) or public cloud (available to many organizations) [10-12]. This concept has widely matured in the last couple of years. Nowadays, it means that anything (i.e., data/resources/services) can be hosted over the internet and are available when needed. Key features of the cloud are ondemand service acquisition, global access, resource pooling in addition to elasticity [13-15]. CC provides three platforms: Infrastructure as a service (IaaS) that involves renting fundamental computing blocks that include physical and virtual servers, network, and storage. The second model of cloud is a platform as a service (Paas), it includes software and tools 
(other than underlying storage infrastructure) that include middleware, operating system, database management, and development tools. The third model of cloud is Software as a service (SaaS), it involves hosting the application on the cloud and providing its access to customers over the internet. Hence, it can be claimed that $\mathrm{CC}$ is used to provide huge storage capacity on a remote server that can be accessed globally [1620] as shown in Fig. 2. CC work in hand with big data concept that is used for handling huge amount of data and extracting useful information.

The term big data (BGD) is used for the collection of data that is large and is still increasing exponentially. This data is so huge and complex that traditional mechanisms of data management are not able to process and store it efficiently. Some example of BGD includes American stock exchange market that generates about one TB data per day, Facebook where 500 plus TB data is ingested into the database every day [21-23]. How to determine that data is big or not? It is often determined using 10V's, which include volume, value, velocity, variety, veracity, variability, vulnerability, volatility, validity, and visualization, as shown in Fig. 3. For the data to be called BGD, it should satisfy a maximum of the above $10 \mathrm{~V}$ 's which means that mere data in huge size is not considered to be BGD [24-27]. The processing of BGD brings multiple benefits for organizations; these benefits include: utilizing outside intelligence in decision making, improving customer service, early risk identification and mitigation, and better operational efficiency [28-29].

The three approaches IoT, CC, and BGD mentioned above usually deal with each other. IoT plays the role of data provider as IoT technologies collect a huge amount of data from various interconnected IoT devices, Cloud provides the storage and management for this data, and BGD involves the processing of this data for extracting useful information. There exist a complementary relationship between IoT and CC. IoT generates a large amount of data while the cloud facilitates data transfer and navigation over the internet [30-33]. IoT also has a complementary relationship with BGD in which data generated from IoT sensors is fed into BGD systems for analysis and report generation. On the other hand, $\mathrm{CC}$ and BGD have an inherent connection with each other [34-39]. Therefore, the convergence of these three approaches can bring improvement in various real-life applications if they are aligned in the best way. Some benefits that can be leveraged while combining all three approaches include: Increase in ROI for the business sector, smarter healthcare industry, rise in self-service analytics, and wide adoption of edge computing [40-43]. In this paper, we have mainly targeted healthcare as it is one of the most significant sectors of the economy. We have provided the contribution of IoT, CC, and BGD in promoting the healthcare industry by providing various statistics from peer-reviewed journals and other well-known sources.

Table I provides a comparison between IoT, CC, and BGD and provides a brief overview of all three approaches. This will help in getting an overview of all three paradigms quickly [4454]. Although these three approaches have their purpose and importance, however, the convergence of these three is very beneficial in real-time applications.

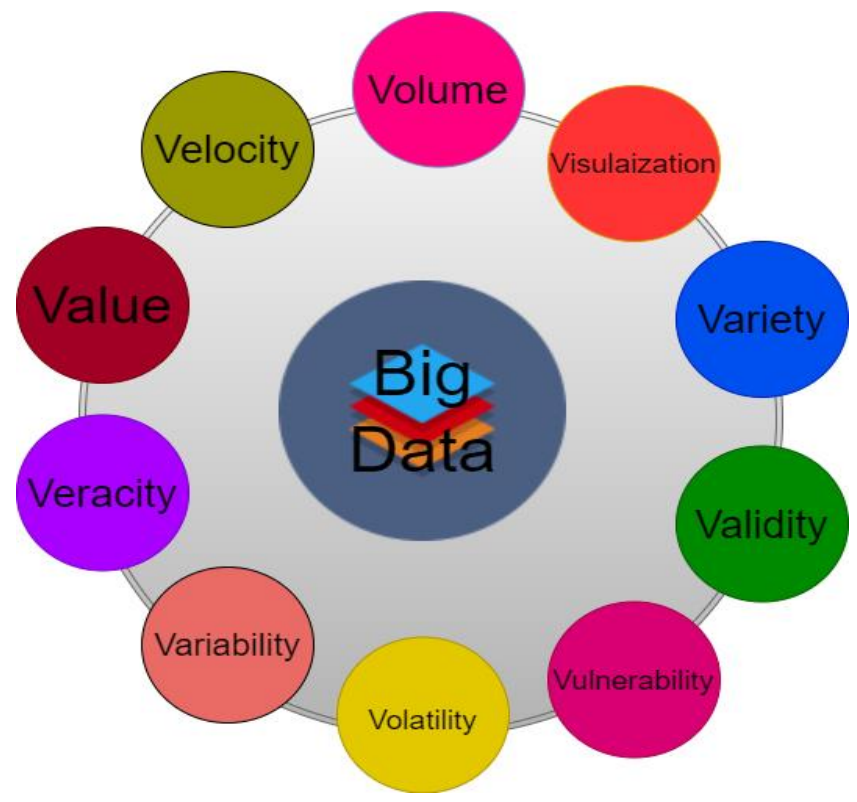

Fig 3. 10 V's of Big Data.

TABLE I. Overview of IoT, CC and BGD

\begin{tabular}{|c|c|c|c|}
\hline Items & IoT & $\begin{array}{l}\text { Cloud } \\
\text { Computing }\end{array}$ & Big Data \\
\hline Definition & $\begin{array}{l}\text { Pervasive: } \\
\text { Interconnecting real- } \\
\text { world objects }\end{array}$ & $\begin{array}{l}\text { Ubiquitous: } \\
\text { Virtual } \\
\text { resources } \\
\text { accessible from } \\
\text { everywhere } \\
\end{array}$ & $\begin{array}{l}\text { Provide ways } \\
\text { to handle a } \\
\text { huge volume } \\
\text { of data }\end{array}$ \\
\hline $\begin{array}{l}\text { Computational } \\
\text { capabilities }\end{array}$ & Limited & $\begin{array}{l}\text { Virtually } \\
\text { unlimited }\end{array}$ & Unlimited \\
\hline Purpose & $\begin{array}{l}\text { Providing } \\
\text { interconnectivity of } \\
\text { real-world objects }\end{array}$ & $\begin{array}{l}\text { Enable data } \\
\text { storage, } \\
\text { processing, and } \\
\text { accessibility }\end{array}$ & $\begin{array}{l}\text { Extracting } \\
\text { hidden } \\
\text { valuable } \\
\text { knowledge } \\
\text { from huge } \\
\text { data }\end{array}$ \\
\hline Working mode & network & $\begin{array}{l}\text { Distributed } \\
\text { computing }\end{array}$ & $\begin{array}{l}\text { Using the } \\
\text { internet for } \\
\text { providing } \\
\text { cloud bases } \\
\text { services }\end{array}$ \\
\hline Benefits & $\begin{array}{l}\text { Automation of daily } \\
\text { tasks and round the } \\
\text { clock monitoring, } \\
\text { total transparency }\end{array}$ & $\begin{array}{l}\text { Low } \\
\text { maintenance, } \\
\text { backup facility, } \\
\text { centralized } \\
\text { platform }\end{array}$ & $\begin{array}{l}\text { Scalable, } \\
\text { robust and } \\
\text { cost-effective } \\
\text { parallelism }\end{array}$ \\
\hline Challenges & $\begin{array}{l}\text { Availability, } \\
\text { security, privacy }\end{array}$ & $\begin{array}{l}\text { Security, } \\
\text { availability, } \\
\text { transformation }\end{array}$ & $\begin{array}{l}\text { Data variety, } \\
\text { data storage, } \\
\text { and resource } \\
\text { management }\end{array}$ \\
\hline
\end{tabular}

In this paper, we have tried to investigate the IoT contribution in BGD and $\mathrm{CC}$. We have provided real-time statistics about the rapidly growing trends of IoT, $\mathrm{CC}$, and BGD with especial focus on the healthcare industry. We have also investigated that the convergence of these three paradigms can be best to leverage the maximum benefit from these latest technologies. We have also provided some statistics about how IoT is contributing to BGD and CC market, especially in the healthcare domain. In the end, we have provided a conceptual framework that shows the relationship between IoT, $\mathrm{CC}$, and BGD. 
The remaining part of this research paper is structured as: Section 2 describes related work that involves emerging IoT and its real-time applications, emerging $\mathrm{CC}$ and its real-time applications and emerging BGD and its real-time applications to give a deeper insight of three approaches to readers. Section 3 describes the analysis of real-time applications that are using these three approaches. Section 4 provides results analysis and discussion followed by Section 5 that concludes the paper. Section 6 highlights the direction for future work.

\section{RELATED WORK}

This section will provide a deeper insight into the convergence of IoT, CC, and BGD and how these three approaches are being used in various application domains, especially in healthcare. Below we provide some deeper insight about all three approaches separately in subsequent subsections

In [55], discusses the excessive usage of IoT, along with associated benefits and challenges. According to this paper, IoT devices generate a huge amount of heterogeneous data through distributed sensors. The acquisition, integration, storage, and processing of this huge amount of heterogeneous data is a challenge for organizations in achieving their desired goals. The paper also discusses the characteristics of IoT data in cloud platforms by providing a framework for the acquisition, storage, integration, and processing of IoT BGD. It discusses the key characteristics of several technical modules associated with it. Further, current research in IoT is analyzed along with associated challenges and opportunities of IoT BGD and some future work is proposed based on research analysis.

According to [56], healthcare data is very sensitive; therefore, it needs automation to make it error-free, and IoT provides a solution towards this end by connecting humans, devices, machines, and systems. Further, these interconnected IoT devices provide patient's data monitoring and transmission that make it easy for the caregivers to provide timely treatment to the patient. Some key benefits associated with using IoT in healthcare involve quick data access, real-time patient monitoring, and timely and fast data transmission. However, these interconnected IoT sensors generate numerous data daily; therefore, the cloud is a good solution for storing this data so that it might be accessible all the time. This paper proposes a framework named IoT-cloud that helps transfer patient's information safely. All the stakeholders involved in the healthcare process are interconnected via a network that makes collaboration easy. The proposed framework possesses the feature of fast data transmission, save delivery time and cost. However, these benefits are associated with the risk of security and trust in addition to various technical issues.

In [57], designed an architectural model for monitoring the health of students by carefully analyzing the health data received. According to the authors, IoT has brought positive changes in almost every field of life, especially healthcare. Moreover, incorporating mobile computing with the IoT system has transformed it from the reactive care system to proactive. A three-phase framework has been proposed in this study. In phase 1 of the framework, medical data of students was collected from various sensors and medical devices, and this data was relayed on the cloud using a gateway or LPU (local processing unit). Phase 2 is concerned with utilizing the received data and taking cognitive decisions related to the health of the student. Phase 3 provides alert to parents and caretakers and also generate alert to nearby hospitals in case of emergency. To validate the proposed framework, a case study was performed that shows that the proposed scheme is effectual in decision making by providing patient's data timely to the caregivers.

In [58], proposed an architecture for IoT based ECG monitoring system that involves three main parts. Part 1 is ECG sensor network that collects data, and Part 2 is IoT cloud that is used to provide storage to the massive data that is generated from IoT sensors namely BGD and part three is a graphical user interface that is a web app used by the caregiver to access the data and provide remedies. In the proposed architecture, the patient's data is gathered from wearable ECG sensors and transferred directly to the cloud using Wi-Fi. All the terminal with smart devices can access this cloud data. An experiment was carried out to test the proposed architecture; the outcomes of the experiment show that the proposed system is reliable in the timely collection of ECH data and thus help in early diagnosis.

In [59], proposed an IoT cloud-based framework for the processing of BGD in the domain of healthcare. According to this paper, IoT, cloud, and BGD are very useful in almost all applications, but their integration in the field of healthcare has brought a good revolution. The proposed model was implemented on amazon cloud operator and used Raspberry pi as an IoT device for generating real-time data. The solution was tested for ECG application by monitoring and reporting abnormalities. The performance of the proposed system was analyzed in terms of response time by changing the volume and velocity of the analyzed data. The proposed model provides good results in terms of response time at a low cost.

According to [5], IoT, CC, and BGD are three main paradigms of ICT. The best features of these three paradigms can be combined for improving next-generation healthcare systems. This study provides a review on the convergence of IoT, CC and BGD paradigm and proposed an M2M system that is based on decentralized cloud infrastructure for e-health applications. The proposed system was built for processing of BGD generated from sensors in such a way that data could be aggregated for generating virtual sensors, the results of some measurements were also presented in the study.

A cloud-IT framework in healthcare has been proposed in [14], according to which the key challenge faced by healthcare is storage, processing, and retrieval of patients' data in the shortest time. This challenge can be addressed by integrating IoT and CC. The proposed framework architecture has four main components, which include: 1) stakeholder devices, 2) stakeholder requests, 3) cloud broker and 4) network administrator. The proposed model aimed to find the best selection of virtual machines so that execution time, waiting time, and turnaround time taken by medical requests might be reduced and task scheduling, patients' data access may be improved through maximum utilization of resources.

According to [60], IoT devices have been widely used in industrial sectors and they have a good impact on performance. These IoT devices generate a large amount of heterogeneous 
data. The storage, retrieval, and management of this data is a big challenge. This study provides a data storage framework in the CC environment for efficient storage and retrieval of data. This framework consists of four modules and provides a facility for combining various types of databases and provide unified data accessing the interface. The data is stored in different databases depending upon the nature of data. However, it can be operated by using the same interfaces. The proposed framework was tested using a real-life case study and results were positive in terms of efficient data storage and access. The authors also claim that the proposed IoT based data storage framework using a cloud platform can be used in a variety of real-life applications.

According to [61], IoT devices are widely used in almost all real-time applications. These IoT devices generate massive data, this data must be processed in an efficient way to get maximum benefits from it. The processing of this massive data is not possible at the IoT end due to the limited computing capability of IoT devices. The solution to this problem is CC, the integration of IoT and could computing has been termed as the cloud of things (CoT) in this paper. The provision of integrating IoT and CC is very useful for the better use of resources. At the same time, this integration is associated with key challenges that include energy efficiency, protocol support, resource allocation, IPV6 deployment, identity management, service discovery, and, most importantly, security and privacy.

In [62], proposed a health monitoring framework using IoT and cloud. According to this paper, IoT devices are widely been used in various real-life applications, especially in healthcare. These IoT sensors generate massive data that is not feasible to store on local servers therefore cloud service is needed. According to this paper, the convergence of IoT and $\mathrm{CC}$ is useful as both these approaches are complementary. The feasibility of the proposed framework was evaluated for the voice pathology monitoring case study. Voice signals were captured using IoT sensors and sent to hosting smart devices. The hosting device directs the signals to the cloud, these signals were authenticated before processing. The processed data is accessible by a caregiver for analysis and decision. The proposed system proved its accuracy; however, some challenges need to be addressed. These challenges include security, availability, scalability, and interoperability.

According to [14], the research on BGD, especially in the field of healthcare, is getting more attention in the past few years. The adoption of IoT, cloud, and BGD in the healthcare field has brought significant improvement. The convergence of IoT and CC contributes well to a BGD environment, especially in the context of Industry 4.0 applications. However, the cloud resources for managing BGD are not sufficient in industry 4.0. To overcome this challenge, a model is proposed to enhance healthcare performance by reducing execution time, BGD storage optimization and by providing a real-time mechanism of patient's data retrieval. The proposed model improves health services in IoT-cloud and industry 4.0 based environments through an optimized selection of virtual machines.

According to [23], wearable medical sensors generate massive data, often called BGD, that is usually the mixture of both structured and unstructured data. The processing and analysis of this BGD for decision making in healthcare are difficult due to the density and heterogeneity of data. To overcome this challenge, this paper provides an architecture for IoT implementation to store and process BGD for healthcare. The proposed architecture consists of two sub-architecture: meta-for-redirection (MF-R) that is used for collection and storage of BGD generated from IoT sensors and grouping and choosing (GC) architecture that is for securing integration of fog computing with that of $\mathrm{CC}$. The proposed architecture was assessed using the parameters of throughput, accuracy, and sensitivity.

According to [59], interoperability is a major burden for IoT system developers. To overcome these challenges, a model is proposed that offers interoperability for BGD collected through various types of IoT devices. The proposed model was tested using two datasets, one dataset consist of diseases along with drug details and the second data set contains drugs and their side effects. The symptoms of diseases were collected from heterogeneous IoT sensors and the SIBM-IoT model suggests drugs and its side effects under the supervision of a concerned physician. A key feature of the proposed model is that the physician can know the condition of the patient anytime from his IoT device.

In [63], provide the convergence of IoT, CC, and BGD for e-health application. According to this study, BGD is collected from ultraviolet sensors attached to the human body. This heterogeneous data will be stored and processed on the cloud and will be accessible by the devices of a relevant person. An architecture is proposed in the study to collect e-health BGD in real-time from various IoT sensors and actuators and transport it to the cloud server for further data processing. The proposed model was evaluated using simulation, and obtained results were satisfactory in terms of secure IoT BGD transmission using CC.

According to [64], managing huge amounts of data (BGD ) generated via IoT sensors is a great challenge in almost every real-life application. However, it becomes more difficult in the healthcare sector as data of the healthcare sector is sensitive and critical, and there is a tremendous increase in this data. The BGD related to healthcare is estimated to be 25000 petabytes in the year 2020. Managing such a huge amount of BGD suffer from the challenges of integrity and confidentiality. To save BGD, there are three options of using a cloud: keeping it on a private cloud, public cloud, or hybrid cloud. For healthcare data, a hybrid cloud option is better as privacy-sensitive data can be stored on the private cloud, and de-identified data can be stored in public cloud so that it might be easily accessible for collaborators for processing.

In the above section, we have presented the emerging role of IoT, CC, and BGD in real-time applications with a special focus on a healthcare application. IoT, CC, and BGD are three key paradigms of modern ICT, along with their associated benefits and drawbacks. However, these three approaches are somehow complementary. IoT devices have widely been used in various domain, including healthcare. These IoT devices are mainly ultraviolet sensors that are attached to the patient's body for tracking and monitoring a patient's health condition. IoT sensors generate a huge amount of data daily. This huge 
amount of data is not possible to be processed on these IoT devices due to the limited computational capabilities of IoT devices. Therefore, the huge amount of generated data from these IoT devices is stored on the cloud [24,40,48,51,55,58,60]. IoT and $\mathrm{CC}$ are complementary because $\mathrm{CC}$ provides the Pathway for the transmission and processing of massive amounts of data generated from IoT devices. In the same way, $\mathrm{CC}$ and BGD are in the same nutshell with IoT. The huge amount of data generated from IoT sensors is stored on the cloud. However, the efficient and cost-effective processing and analysis of this data to get useful information is also a challenge that can be solved using BGD systems. Various service providers like Google, Microsoft, and AWS are offering their BGD systems at an effective cost. These systems are also scalable and customizable according to organizational needs $[12,18,38,47]$. This shows that these three technologies need to be converged to get maximum benefits for real-time applications as they exist in a nutshell.

\section{REAL-TIME APPLICATION ANALYSIS}

In this section, we will use existing statistics from some valuable sources to provide a comprehensive insight into the three ICT paradigms, namely IoT, CC, and BGD. This will also help the researchers and practitioners about knowing the importance of three paradigms individually as well as in a nutshell.

To get the deeper insight about above mentioned three key ICT paradigms, in the following subsections we have provided details about how these three paradigms are growing in various real-life applications with special focus on the healthcare industry. We have provided real data statistics to show the market share and emerging trends in all three paradigms. IoT has contributed a lion share in BGD and $\mathrm{CC}$ by providing connectivity between all real-life objects.

\section{A. Real-Time Application Analysis for Recent IoT Application}

IoT has brought changes in almost every field of life. Broadly we can categorize IoT into two categories, namely industrial IoT and consumer IoT. Key Industrial IoT applications include manufacturing, energy \& utilities, healthcare, retail, government, and public services, insurance, mobility, and telecommunication, etc. IoT has provided a lot of ease in automating all these sectors. Consumer IoT involves connected homes, connected cars, health \& lifestyle, and entertainment. Keeping the importance of IoT in almost every real-time applications, all the developed and developing countries are investing a lot in these IoT devices. Fig. 4 shows the investment on IoT devices worldwide in various sectors in 2015 and now in 2020

The graph in Fig. 4 shows that there is a remarkable increase in IoT devices worldwide. This shows that IoT is affecting almost all real-time applications positively. The data of Fig. 4 is taken from the Statista website that is a German online portal for providing the latest statistics by collecting data from various industries on a real-time basis. The same company has provided its statistics about IoT devices connected worldwide from the year 2015 to 2020 and estimated for the next five years based on the prediction gained from data. Graph of Fig. 5 shows the number of installed IoT devices worldwide from the year 2015 o 2025.

As discussed before, in this paper, we are mainly targeting the healthcare industry, so now we discuss some current statistics about the usage of IoT devices in the healthcare sector. Fig. 6 shows the estimated IoT devices installed in the healthcare sector from 2015 to 2020. The data of the figure is taken from the Business Insider website that is one of the wellknown business, and financial news websites founded in the year 2009 and is owned by the German publishing company Axel Springer SE [67].

The graph of Fig. 6 shows that there is a great rise in the use of IoT technologies for healthcare applications. The size of the healthcare market is also increasing tremendously, and it is expected that in 2025, it will increase to 135 billion USD worldwide. Fig. 7 provides a projection about an increase in the IoT healthcare market from 2016 to 2025[68]. The data of Fig. 7 is taken from Statista.

\section{Spending on IoT worldewide in 2015 and 2020 in billion USD}

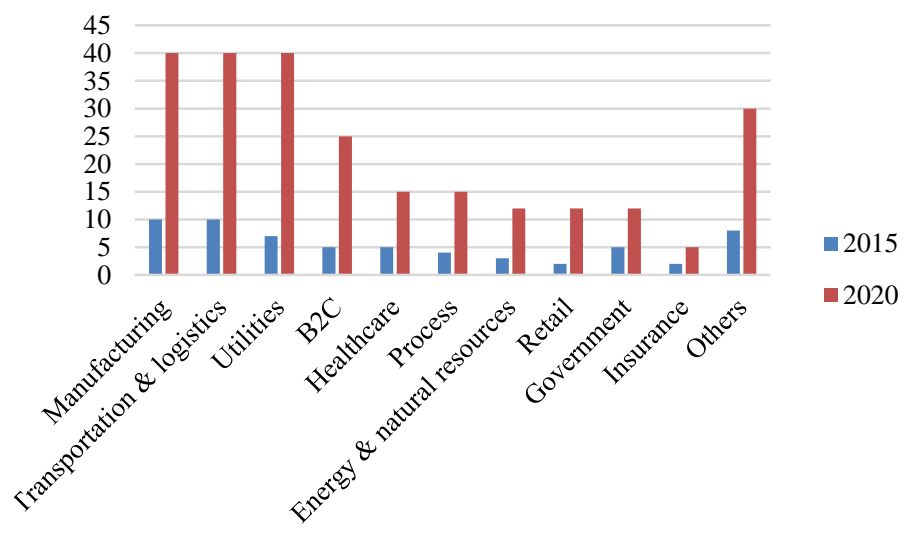

Fig 4. The Tremendous Growth of IoT Worldwide [65].

\section{IoT connected devices worldwide}

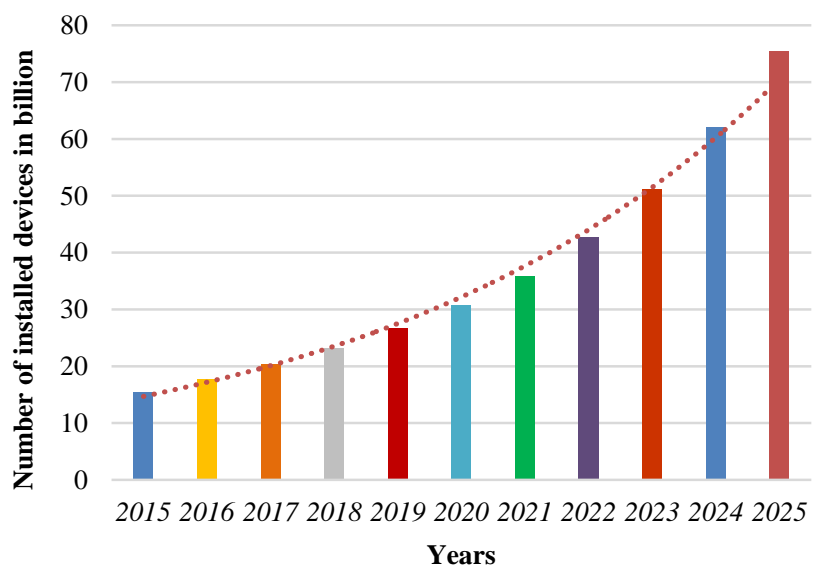

Fig 5. IoT Connected Devices Worldwide [66]. 


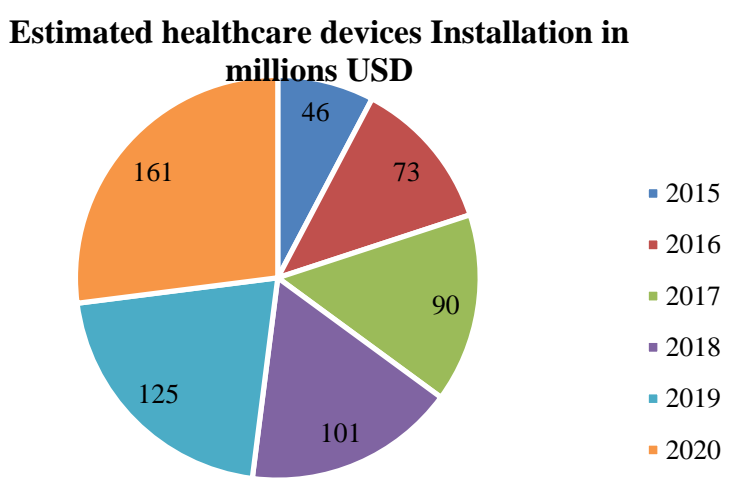

Fig 6. Estimated IoT Devices Installation in Healthcare [67].

\section{Projected size of IoT in healthcare market worldwide}

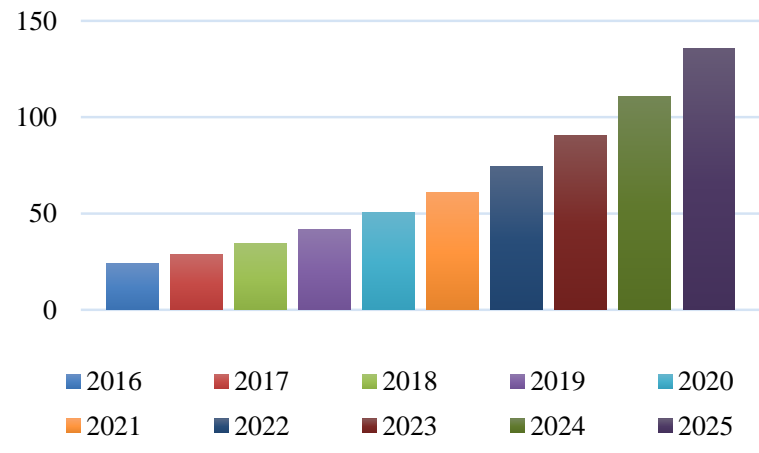

Fig 7. Prediction of Increase in IoT Healthcare Market Size [68].

An important use of IoT in healthcare is wearable devices. These devices are worn by patients or normal human beings for monitoring their health conditions. According to a survey provided by the Statista research department in February 2020, the number of wearable devices will increase three times as compared to the number of wearable devices currently been used. Fig. 8 provides the estimated statistics of wearable devices

\section{Estimated Wearable dvices worldwide by} region from $2015-2022$

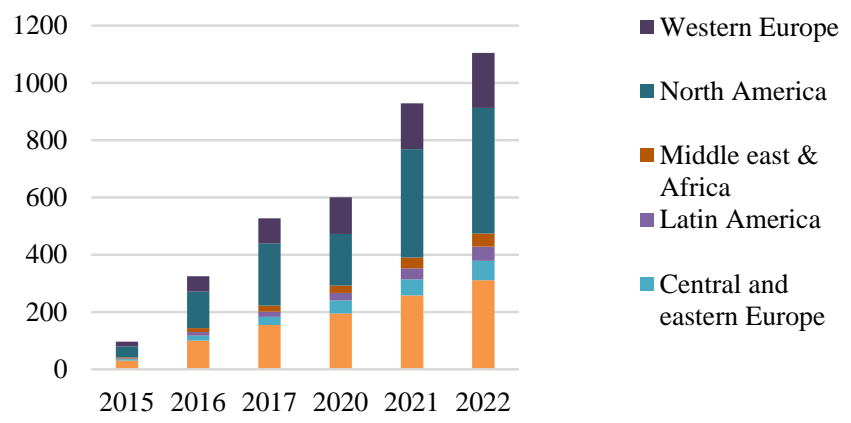

Fig 8. Estimated Wearable Devices Region-Wise in millions [69].
According to the graph in Fig. 8, North America is forecasted to be the region with the highest number of $5 \mathrm{G}$ connected devices in 2022. The number of $5 \mathrm{G}$ connections made in North America will be 439 million more than the $4 \mathrm{G}$ connections made in 2017. The aggregative forecasting of wearable devices in North America and Asia pacific will be around $70 \%$ of all the wearable devices used worldwide in 2022.

According to a report published by Statista, one of the trusted firms for syndicate research services, the number of wearable device market share is increasing with time. According to this report, the increasing trend of wearable devices has improved its market share a lot as shown in Fig. 9.

Statista has also provided the estimated share of wearable devices from 2017 to 2019 worldwide and also predicted it for the year 2022 as shown in Fig. 10.

According to Fig. 10, ear-worn and smartwatches have a maximum share in the global wearable market. Statista has also forecasted wearable patient monitoring devices statistics region wised as shown in Fig. 11. According to Fig. 11, North America is having the largest market share, followed by Asia pacific. This might be due to a large number of aged populations and advanced medical infrastructure.

\section{Projected wearable devices shipmenr worldwide}

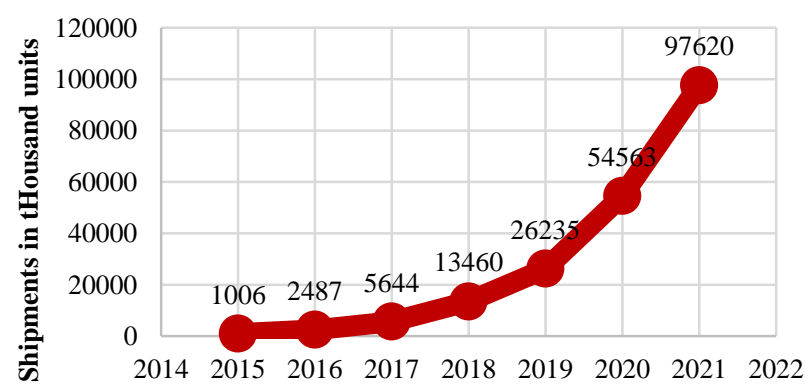

Fig 9. Projection of Wearable Devices Market Share [70].

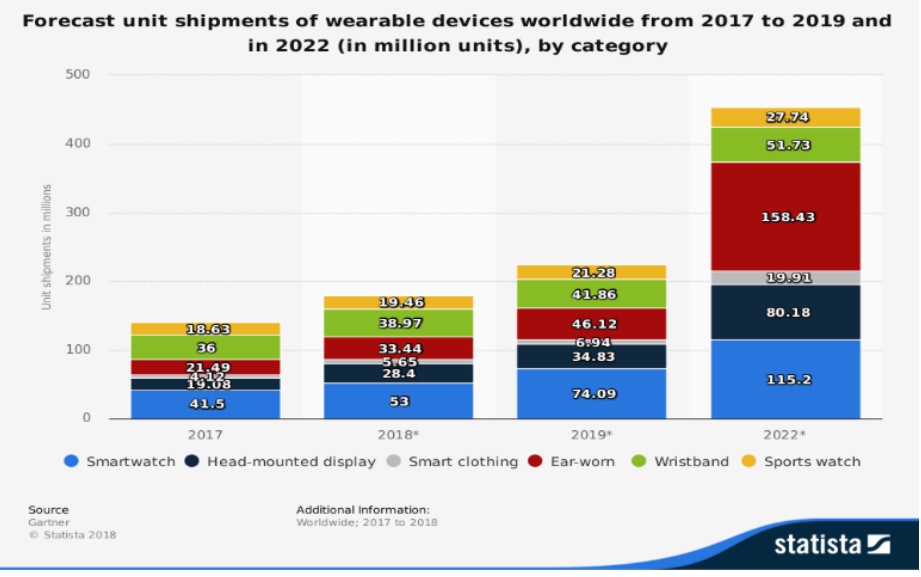

Fig 10. Prediction of Different Wearable Devices Share in the Market Worldwide [71]. 


\section{Wearable devices worldwide by region in million}

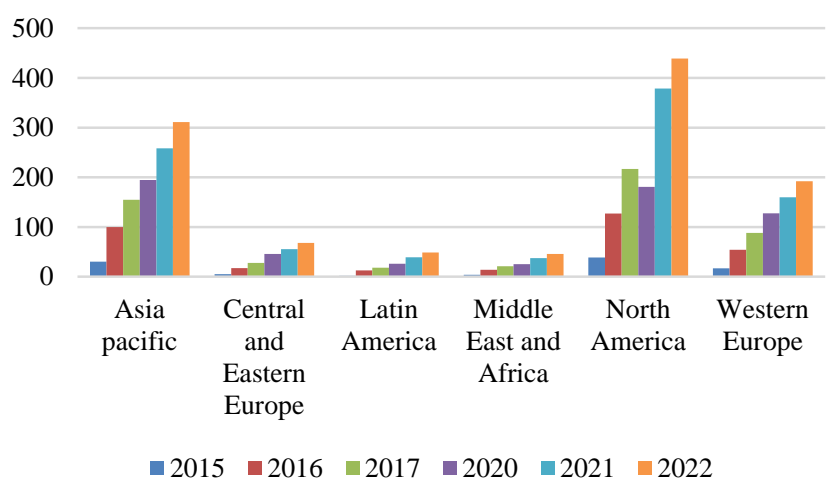

Fig 11. Patient Monitoring Devices Share Region Wise [72].

The above statistics show that IoT devices are widely used in the healthcare market and its share is increasing with time. People, especially those living in the developed region, prefer to utilize the facility of remote monitoring and mobile health. Moreover, the new development in the healthcare sector is mainly based on advanced medical infrastructure in which the whole process is automated from end to end.

\section{B. Real-Time Application Analysis for Recent Cloud Computing (CC) Application}

The tremendous growth of real-time data generated daily demands huge and secure storage mechanism that provides global access to data. CC is a solution to this end. It is a technology that uses remote servers and the internet to manage data and applications. CC allows users to use applications without installation and 24/7 data accessibility. CC not only provides hosting services rather it possesses some salient features such as scalability, cost-effectiveness, high security, global access, reliability, and platform independence that make it special. Clouds are usually owned by the largest corporations such as Microsoft, Apple, and Amazon, etc.

Some of the broad categories of cloud services include IaaS, PaaS, Saas, and BPasS (business as a service). IaaS is the lowest level of service in which service provider provides the virtual infrastructure that is composed of storage space, servers and various network elements such as load balancers and firewalls. Customers customize this infrastructure according to their requirements and pay a fixed price for this according to the volume of data. PaaS adds one more layer in IaaS by providing an operating system, database, and software servers to customers that customers can configure according to their requirements. SaaS offers access to the application as well. It is also known as on-demand software. SaaS customer does not need to worry about hosting, installation or maintenance of application rather service provider is the one who is responsible for all these issues. BPasS is one layer above SaaS and provides business processes that are cross-functional such as payroll management. It also provides coordination between several applications hosted on the cloud or the organizational infrastructure.

\section{Cloud service revenue wordwide in billion USD}

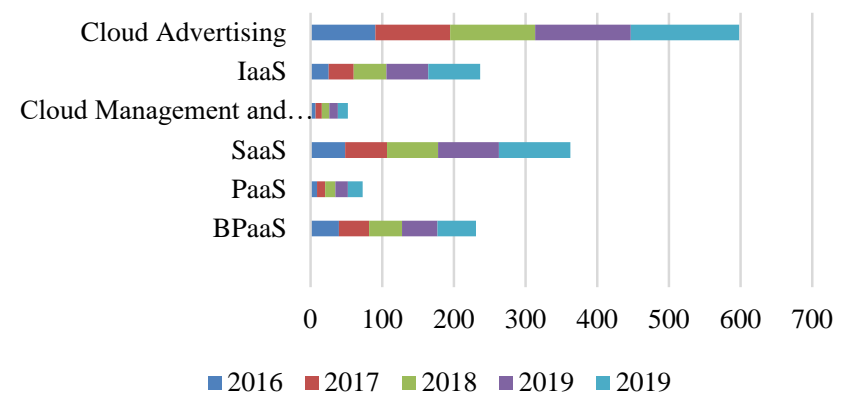

Fig 12. Revenue Achieved through Various Cloud Services Worldwide in billion USD [73].

\section{Prediction of cloud penetration in healthcare}

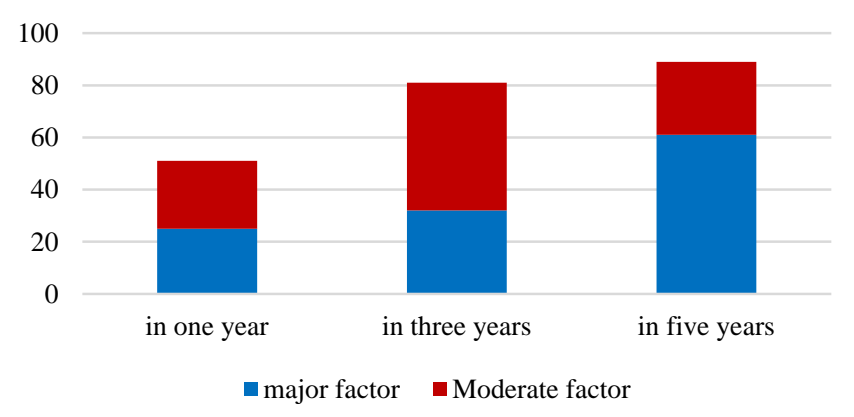

Fig 13. Prediction of CC Market Size for Healthcare Industry [74].

According to a report presented by Gartner in October 2017, the CC market is tremendously increasing all over the world as shown in Fig. 12. The total market share of the CC market is predicted to be almost double 411.4billion USD in 2020 as compared to 2016 where it was 219.6 billion USD.

If we analyze the data from Fig. 12, the highest revenue is generated by the IaaS platform that was projected to grow 35 $\%$ more in 2020 as compared to 2016. Cloud advertising is also contributing a lion share in the revenue generated by CC.

$\mathrm{CC}$ is providing its services in almost all real-time applications. Healthcare is one such industry that benefited a lot from cloud services. CC has increased the efficiency of the healthcare industry by reducing costs. It provides easy and secure medical record sharing, automation of backend operations and helps in the creation and maintenance of telehealth apps.

According to the survey provided by [74], the cloud technology is penetrating in the healthcare industry as a major factor in upcoming years as shown in Fig. 13

In [75], provided the region-wise market size of $\mathrm{CC}$ in the healthcare area as shown in Fig. 14. According to it, North America is having the largest share in the healthcare CC market followed by Europe that is second in the list. The large share in these regions is attributed to the rapid adoption of electronic health records, incentive-driven approaches provided by the government and private-public partnership. 


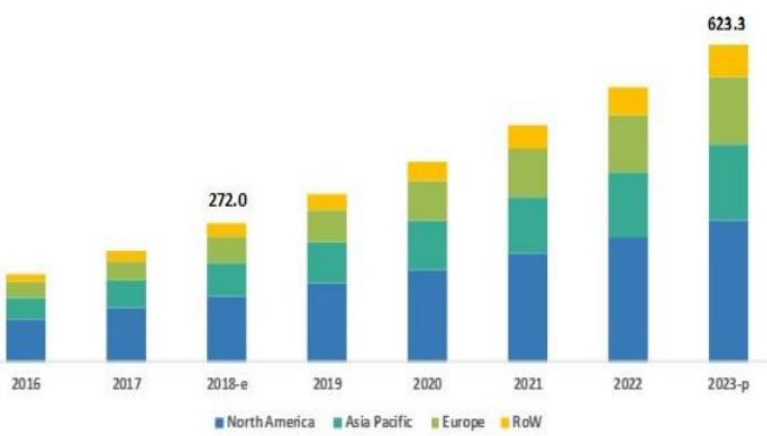

Fig 14. Healthcare CC Market Region-Wise in billion USD [75].

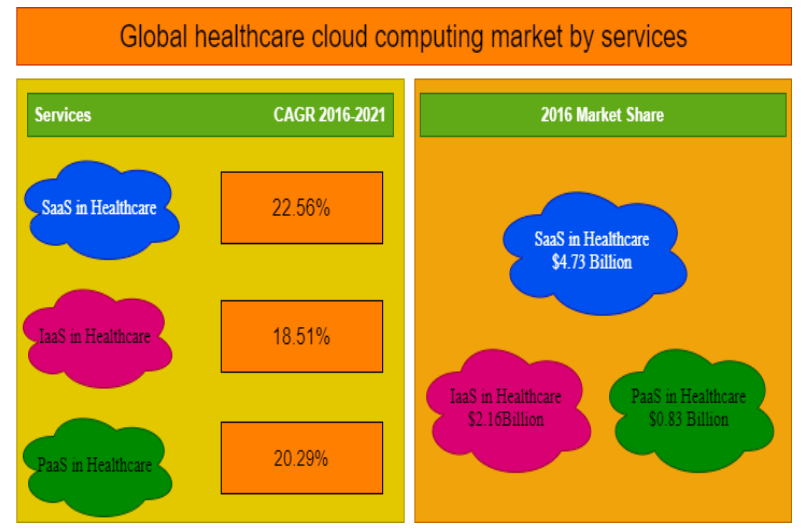

Fig 15. Market Share of CC in Healthcare [76].

Technavio one of the leading global technology advisory and Research Company has published a report titled 'Global Healthcare CC Market 2017-2021'. This report provides a complete overview of the market trend regarding the adoption of CC in healthcare. Fig. 15 provides the highlights of this report, according to this report SaaS is having more shares in the healthcare market and it is expected to be $23 \%$ of total Compound annual growth rate (CAGR). The reason for excessive SaaS usage in the healthcare market is that a SaaS solution takes less time in implementation as compared to onpremises solutions. The most demanded solutions in the healthcare sector are those which are powered by analytical tools. On the other hand, IaaS is expected to grow at a CAGR of above $18 \%$ in the healthcare sector. A key factor that motivates IaaS adoption in healthcare is its flexible pricing model and storage space. While PaaS is expected to contribute more than $20 \%$ in global CAGR [76].

This report also highlights that the cloud healthcare market is booming in cardiology due to the rising volume of license renewal of medical software and subscriptions. Mostly, the cardiac hospital uses cloud services for quick retrieval of patient's data. According to this report, the demand for CC in the healthcare sector is increasing with time.

IoT contributes a lion share in the $\mathrm{CC}$ market, and this trend is increasing with time due to the rapidly growing use of IoT in almost every field of life. According to a survey published in August 2019 by Parser, the common cloud platform for IoT is Amazon web services, Microsoft Azure, and Google cloud platform. Fig. 16 provides the statistics of various cloud platforms used for IoT from 2016-2018 [77].
Types of cloud services for IoT

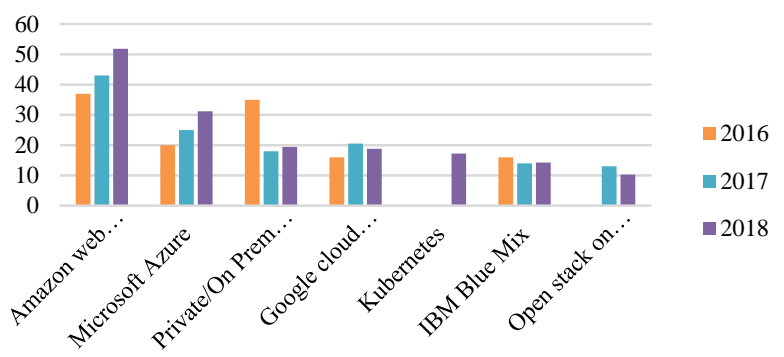

Fig 16. Cloud Services used for IoT.

The above discussion shows that $\mathrm{CC}$ demand in the healthcare industry is rising with time. A lot of healthcare service provider is using CC due to the flexibility of storage and pricing options, timely and global availability of data, and reliability of services. Some of the key benefits associated with the use of CC in healthcare include better collaboration, better storage, greater reach, better use of BGD for patients' treatment, and improved medical research.

\section{Real-Time Application Analysis for Recent Big Data Application (BGD)}

BGD refers to the aggregation, transformation, and manipulation of data that is huge and complex, and it is difficult to process this data using conventional data processing mechanisms. It is processed using data scientists and machine learning algorithms. The concept of BGD raised in the 2000s when a new definition of BGD was articulated using three Vs, namely volume, variety and velocity of data. Now, these Vs reached 10 which we have highlighted in the introduction section using Fig. 3.

According to the report published by Statista, the revenue generated from the BGD market is estimated to increase from $\$ 42$ billion in 2018 that was $\$ 103$ billion in 2027, attaining a CAGR of about $10.48 \%$ as shown in Fig. 17. According to this report, enterprises are discovering new opportunities for cost reduction by using BGD and advanced analytics for better results. It has also been reported by Statista that Hadoop and BGD market is probable to grow from 17.1 billion USD in 2017 to 99.31 billion USD in 2022 that is a good increase in CAGR of about $28.5 \%$.

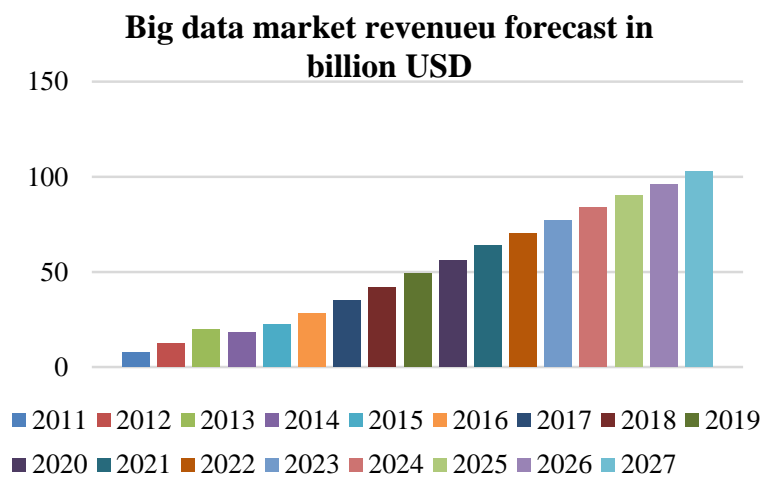

Fig 17. Revenue Forecast of BGD Market from 2011-2027 by Statista [78]. 


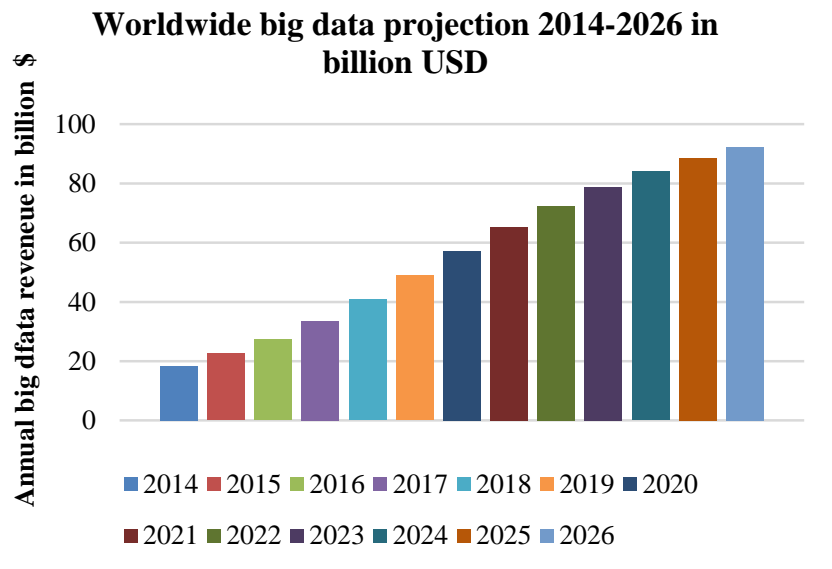

Fig 18. Worldwide BGD Projection from 2014-2026 by Wikibon [79].

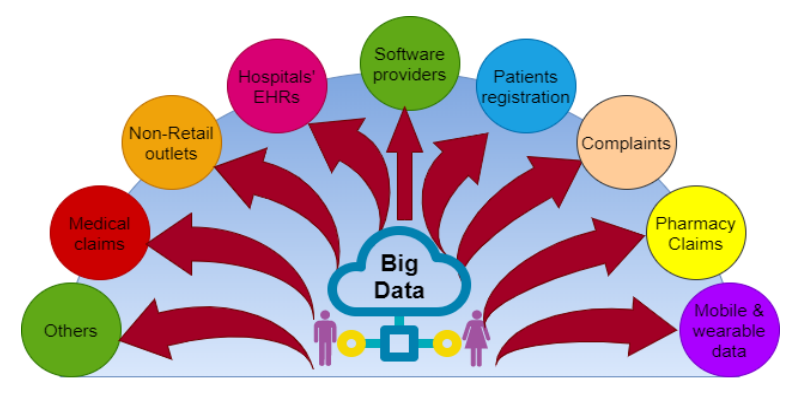

Fig 19. BGD and IoT Applications in Healthcare.

Another report by Wikibon that is a community of consultants and practitioners on business systems and technology, estimated that the worldwide BGD market is expecting to attain a CAGR of $14.4 \%$ in 2026, growing from $\$ 18.3$ billion to $\$ 92.2$ billion. Fig. 18 shows the report of Wikibon BGD project 2016

Fig. 18 shows that the BGD market is gaining a good revenue share in the upcoming years. Although this concept of BGD is applicable in almost all big industries, one of its important roles is in healthcare, where massive data is generated daily from different sources, as shown in Fig. 19. BGD has different uses in healthcare such as medical researchers use BGD on treatment plans and finding out recovery rates of patients from various chronic diseases. Access to bug data provides a more comprehensive picture of patients, supports decision-makers in modeling new healthcare systems, and allows measurement related to patients more accurately.

According to [80], massive data is generated by the healthcare industry from different sources including IoT sensors, hospital records, and results of medical examinations. A significant portion of healthcare data is also generated by biomedical research. This huge amount of data needs proper analysis and management for extracting meaningful information to leverage its' potential benefits. The challenges associated with this huge amount of data can only be surpassed using BGD computing solutions. Therefore, it is considered necessary that the healthcare provider needs to be equipped with suitable infrastructure for systematic analysis and management of BGD.

\section{Projected CAGR of global healthmarket by major segments 2015-2020}

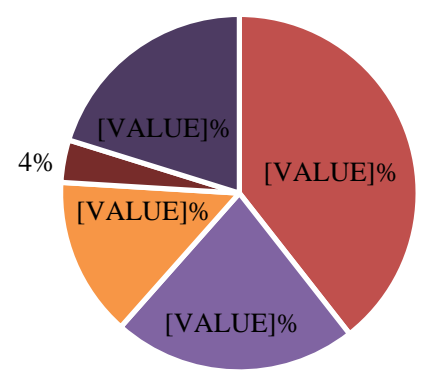

- Mobile health

- wireless health

- Telehealth

- HER/EMR

- Average

Fig 20. Projected CAGR of the Global Healthcare Market by Major Segments [81].

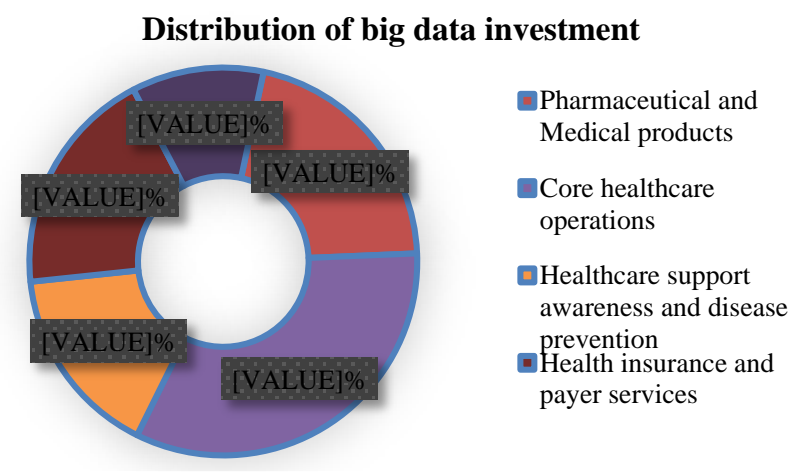

Fig 21. Distribution of BGD Investment in Healthcare \& Pharmaceutical Industry by Application Area [82].

In a report generated by Statista in October 2017, CAGR is predicted for the global health market from the period of 20152020 by using major healthcare segments, as shown in Fig. 20. According to Fig. 20, mobile health contributes a lot in the healthcare sector by having $41 \%$ of the total healthcare CAGR followed by wireless health that contributes to $23 \%$ of CAGR of total healthcare [81].

SNS Telecom \& IT have provided a report in which it was estimated that BGD investment in healthcare and pharmaceuticals industry will contribute to nearly 4.7 billion dollars in 2018 alone and it is expected to attain a CAGR of about $12 \%$ in next three years. Fig. 21 provides the statistics of the healthcare and pharmaceutical industry w.r.t. key application areas. According to Fig. 21, core healthcare operations contribute to $33 \%$ of total BGD investment, followed by pharmaceutical and medical products that are contributing to $21 \%$ of total BGD investment in the healthcare sector.

Although a lot of real-life applications are contributing to BGD, however, data generated from IoT devices contribute a lot. According to a survey provided by Evans Data Corporation, The developers who are planning to provide BGD analytics solutions need to consider IoT the most as can be seen from Fig. 22. According to this figure, IoT devices have a $15.1 \%$ share of the total BGD share in 2016, which means the biggest target for the developers who deal with BGD analytics in the field of IoT [83]. 
Industry share in big data analytics

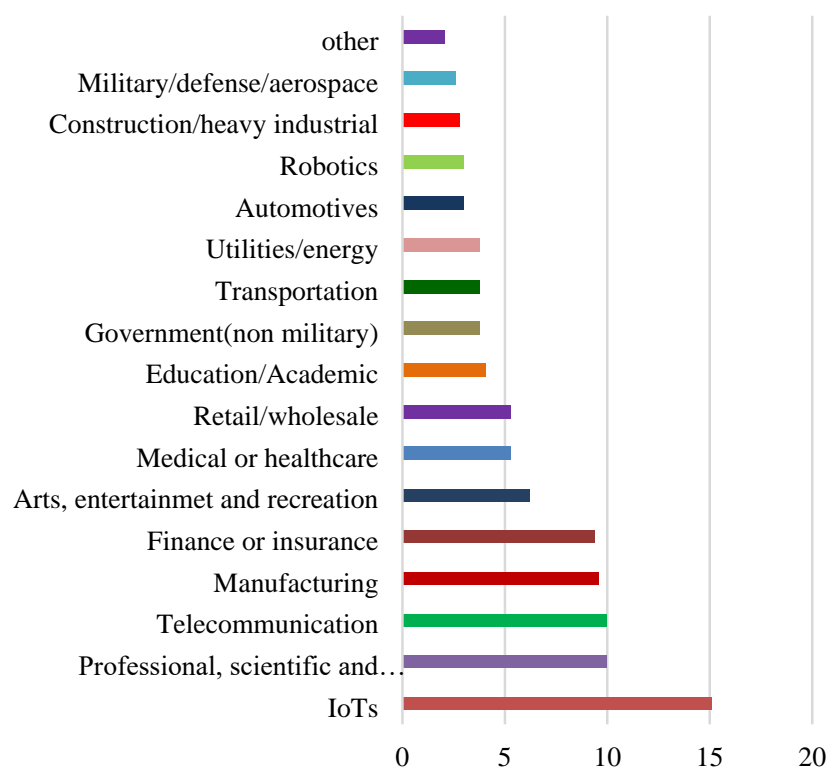

Fig 22. Industry Share in BGD Analytics by Evans Data Corporation.

The above discussion highlights the growing trend and importance of BGD analytics in general and for the healthcare industry in particular. Some of the key challenges faced by healthcare industries worldwide include an increase in the aging population, citizens' expectations and rapidly growing use of technologies. Improving healthcare efficiently and costeffectively is a concern of the healthcare industry worldwide, BGD provides the solution to this problem by providing the ability to detect patterns and extracting useful information from the huge volume of data.

\section{FINDINGS AND DISCUSSION}

In the above subsections, we have provided a detailed overview of emerging applications of IoT, CC, and BGD with a major focus on IoT share in CC and BGD. The IoT is contributing much in almost all real-life applications. This paper mainly focuses on the healthcare industry. Each of these three technologies has problems such as difficulties in installation, poor scalability, security, maintenance, low performance, fault tolerance, etc. However, we can leverage the maximum benefits by converging these paradigms. CC and BGD have inherent connections between them as services of the cloud are required for storing and managing BGD, while IoT serves as a data source unit.

IoT has evolved the concept of the internet network, which facilitates the communication between multiple objects, including smart devices, sensors, actuators, and others. Using IoT and cloud together provides many benefits which include: cloud infrastructure deploy applications and thus provide quick data analysis and storage facility and make the decisionmaking process easy. The estimated size of IoT data is predicted to be 4.4 trillion GB in 2020 that is difficult to manage, $\mathrm{CC}$ provides a competent solution to this problem by providing acceptable performance and scalability to manage such a huge amount of data. Another complementary relation between IoT and CC is that a large amount of data generated through IoT devices is navigated and accessed easily using a cloud platform. CC helps to improve the monitoring and analytics of IoT devices. IoT devices can receive important security updates quickly from clouds when any security gap appears in the infrastructure. Thus, the combined feature of IoT and $\mathrm{CC}$ is vital for the privacy and security of users [84-87].

IoT and BGD together have created many opportunities, and it is predicted that the IoT industry will gain $\$ 19$ trillion in the next ten years while using BGD systems. IoT enables interaction between machine to machine and human to machine and thus a huge amount of data is generated from sensors. Both IoT and BGD emphasized the need for converting data into useful information that can be acted upon. An example of IoT working in collaboration with BGD comes from the healthcare industry where IoT devices collect patients' vital information and this information is sent to caregivers for immediate actions. However, this information is also stored to get a big picture of the patients' diseases over time. Ultimately, IoT working together with BGD results in improved efficiency, cost-saving and better use of resources [87-90].

CC and BGD are two mainstream technologies these days. Both these technologies are fundamentally different as BGD deal with huge amounts of data and CC is about infrastructure. However, the combination of both is the key reason for huge enterprise adoption e.g. Amazon "elastic map reduces" service shows how the power of cloud elastic computers is leveraged using BGD processing. Some benefits of CC, together with BGD include improved analysis, simplified infrastructure, cost reduction, privacy and security and virtualization [91-95].

The above discussion shows that although IoT, CC, and BGD are three different paradigms with their challenges and benefits. However, these three paradigms are interrelated and can be used together to get maximum benefits in various reallife applications. The healthcare industry can leverage potential benefits by automating the healthcare system using IoT devices, using cloud services to store massive amounts of data that is generated from IoT sensors and getting benefits of BGD systems to extract useful information from huge amounts of heterogeneous data. Fig. 21 summarizes the above discussion by providing a relationship between these three technologies in a conceptual framework

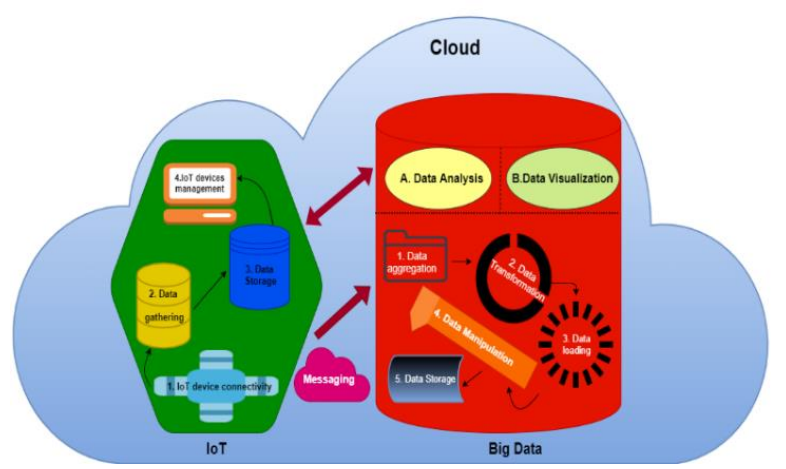

Fig 23. A Conceptual Framework Showing the Relationship between IoT, $\mathrm{CC}$ and BGD. 
According to the conceptual framework shown in Fig. 23, $\mathrm{CC}$ serves as a container and provides a platform for storage of IoT BGD. In real-life applications, billions of IoT devices are interconnected to each other. These interconnected devices gather data from the real-time environment using sensors and actuators and store it. IoT devices do not have strong computational capabilities, however, still, they provide the facility of data management at their end as shown in Fig. 23. IoT communicates with BGD, this communication is both unidirectional and bidirectional. BGD mainly has two modules, namely, the data analytics part and data visualization. BGD system collects data, transform it, manipulate and store it.

\section{CONCLUSION}

IoT, CC, and BGD are three key paradigms of ICT, which are tremendously growing in the past two decades. These three paradigms are also hot topics of research in the current era. Although IoT, CC, and BGD are three different approaches that have their challenges and strengths, these three paradigms are somehow closely related to each other. CC and BGD have coherent relationships as BGD are usually stored and managed via a cloud infrastructure, on the other hand, IoT devices generate massive heterogeneous data that need the cloud for its storage and processing due to limited computational capabilities of IoT devices. Further, massive data generated via IoT devices contribute to BGD. Therefore, the convergence of these three devices can leverage the maximum benefits from it. In this paper, we have discussed the emerging real-time application of IoT, CC, and BGD with special focus on the healthcare industry as it is one of the important real-life applications. We have also provided some statistics from reliable sources to show how these three paradigms are getting market share in the industry. In the end, we have discussed that the convergence of these three paradigms helps to get the maximum benefits from these technologies, and we have provided a framework that shows the relationship between these three paradigms.

\section{FUTURE WORK}

In the future, we are going to apply these three paradigms in a real-life application to find out some statistical facts about the pros and cons associated with this convergence of IoT, CC, and BGD.

\section{REFERENCES}

[1] Alshammari, M.O., Almulhem, A.A., and Zaman, N.: 'Internet of Things (IoT): Charity Automation', International Journal of Advanced Computer Science and Applications (IJACSA), 2017, 8, (2)

[2] Farahani, B., Firouzi, F., and Chakrabarty, K.: 'Healthcare IoT': 'Intelligent Internet of Things' (Springer, 2020), pp. 515-545

[3] Alamri, M., Jhanjhi, N., and Humayun, M.: 'Blockchain for Internet of Things (IoT) Research Issues Challenges \& Future Directions: A Review', Int. J. Comput. Sci. Netw. Secur, 2019, 19, pp. 244-258

[4] Khan, A., Jhanjhi, N., Humayun, M., and Ahmad, M.: 'The Role of IoT in Digital Governance': 'Employing Recent Technologies for Improved Digital Governance' (IGI Global, 2020), pp. 128-150

[5] Suciu, G., Suciu, V., Martian, A., Craciunescu, R., Vulpe, A., Marcu, I., Halunga, S., and Fratu, O.: 'Big data, internet of things and cloud convergence-an architecture for secure e-health applications', Journal of medical systems, 2015, 39, (11), pp. 141

[6] Bhatt, C., Dey, N., and Ashour, A.S.: 'Internet of things and big data technologies for next generation healthcare', 2017
[7] Diro, Abebe, Haftu Reda, Naveen Chilamkurti, Abdun Mahmood, N. Z Jhanjhi, and Yunyoung Nam. "Lightweight Authenticated-Encryption Scheme for Internet of Things Based on Publish-Subscribe Communication." IEEE Access (2020).

[8] Firouzi, F., Rahmani, A.M., Mankodiya, K., Badaroglu, M., Merrett, G.V., Wong, P., and Farahani, B.: 'Internet-of-Things and big data for smarter healthcare: From device to architecture, applications and analytics', in Editor (Ed.) $)^{\wedge}(E d s$.$) : 'Book Internet-of-Things and big data$ for smarter healthcare: From device to architecture, applications and analytics' (Elsevier, 2018, edn.), pp.

[9] Almusaylim, Z.A., Alhumam, A., and Jhanjhi, N.: 'Proposing a Secure RPL based Internet of Things Routing Protocol: A Review', Ad Hoc Networks, 2020, pp. 102096

[10] Zaman, N., Ilyas, M., Ahmad, M., Mohammad, F., and Abdullah, A.: 'An Experimental Research in Health Informatics for Designing an Enhanced Intelligent Could-Based Collaborative Multi-Modal Framework for Medical Imaging Diagnostics', Journal of Medical Imaging and Health Informatics, 2017, 7, (6), pp. 1358-1364

[11] Chen, M., Yang, J., Hu, L., Hossain, M.S., and Muhammad, G.: 'Urban healthcare big data system based on crowdsourced and cloud-based air quality indicators', IEEE Communications Magazine, 2018, 56, (11), pp. $14-20$

[12] Verma, P., and Sood, S.K.: 'Cloud-centric IoT based disease diagnosis healthcare framework', Journal of Parallel and Distributed Computing, 2018, 116, pp. 27-38

[13] Almusaylim, Z.A., and Jhanjhi, N.: 'Comprehensive Review: Privacy Protection of User in Location-Aware Services of Mobile Cloud Computing', Wireless Personal Communications, 2020, 111, (1), pp. 541-564

[14] Elhoseny, M., Abdelaziz, A., Salama, A.S., Riad, A.M., Muhammad, K., and Sangaiah, A.K.: 'A hybrid model of internet of things and cloud computing to manage big data in health services applications', Future generation computer systems, 2018, 86, pp. 1383-1394

[15] Stergiou, C., and Psannis, K.E.: 'Recent advances delivered by Mobile Cloud Computing and Internet of Things for Big Data applications: a survey', International Journal of Network Management, 2017, 27, (3), pp. e1930

[16] D. A. Shafiq, N. Jhanjhi and A. Abdullah, "Proposing A Load Balancing Algorithm For The Optimization Of Cloud Computing Applications," 2019. 13th International Conference on Mathematics, Actuarial Science, Computer Science and Statistics (MACS), Karachi, Pakistan, 2019, pp. $1-6$.

[17] Alhussein, M., Muhammad, G., Hossain, M.S., and Amin, S.U.: 'Cognitive IoT-cloud integration for smart healthcare: case study for epileptic seizure detection and monitoring', Mobile Networks and Applications, 2018, 23, (6), pp. 1624-1635

[18] Hong, J., Morris, P., and Seo, J.: 'Interconnected personal health record ecosystem using IoT cloud platform and HL7 FHIR', in Editor $(\text { Ed. })^{\wedge}(E d s$.$) : 'Book Interconnected personal health record ecosystem$ using IoT cloud platform and HL7 FHIR' (IEEE, 2017, edn.), pp. 362367

[19] Milovanovic, D., and Bojkovic, Z.: 'Cloud-based IoT healthcare applications: Requirements and recommendations', International Journal of Internet of Things and Web Services, 2017, 2, pp. 60-65

[20] Kumar, P., and Silambarasan, K.: 'Enhancing the Performance of Healthcare Service in IoT and Cloud Using Optimized Techniques', IETE Journal of Research, 2019, pp. 1-10

[21] Ge, M., Bangui, H., and Buhnova, B.: 'Big data for internet of things: a survey’, Future Generation Computer Systems, 2018, 87, pp. 601-614

[22] Jagadeeswari, V., Subramaniyaswamy, V., Logesh, R., and Vijayakumar, V.: 'A study on medical Internet of Things and Big Data in personalized healthcare system', Health information science and systems, 2018, 6, (1), pp. 14

[23] Manogaran, G., Varatharajan, R., Lopez, D., Kumar, P.M., Sundarasekar, R., and Thota, C.: 'A new architecture of Internet of Things and big data ecosystem for secured smart healthcare monitoring and alerting system', Future Generation Computer Systems, 2018, 82, pp. $375-387$ 
[24] Zaragoza, M.G., Kim, H.-K., and Lee, R.Y.: 'Big Data and IoT for Uhealthcare Security', in Editor (Ed. $)^{\wedge}(E d s$.$) : 'Book Big Data and IoT for$ U-healthcare Security' (Springer, 2017, edn.), pp. 1-11

[25] Basha, A.J., Malathi, M., Balaganesh, S., and Maheshwari, R.: 'Patient Tracking Using IoT and Big Data', in Editor (Ed.)^(Eds.): 'Book Patient Tracking Using IoT and Big Data' (Springer, 2018, edn.), pp. 613-621

[26] Manogaran, G., Lopez, D., Thota, C., Abbas, K.M., Pyne, S., and Sundarasekar, R.: 'Big data analytics in healthcare Internet of Things': 'Innovative healthcare systems for the 21st century' (Springer, 2017), pp. 263-284

[27] Mihovska, A.: 'Big Data Processing Platform for Healthcare Applications', in Editor (Ed.) $)^{\wedge}$ Eds.): 'Book Big Data Processing Platform for Healthcare Applications' (2018, edn.), pp.

[28] Xu, X., Liu, Q., Luo, Y., Peng, K., Zhang, X., Meng, S., and Qi, L.: ‘A computation offloading method over big data for IoT-enabled cloudedge computing', Future Generation Computer Systems, 2019, 95, pp. 522-533

[29] Yassine, A., Singh, S., Hossain, M.S., and Muhammad, G.: 'IoT big data analytics for smart homes with fog and cloud computing', Future Generation Computer Systems, 2019, 91, pp. 563-573

[30] Ahmad, M., Zaman, N., and Al-Amin, M.: 'An experimental research in health informatics for enhancing ovarian cancer identification in ovarian imaging analysis using fuzzy histogram equalization', Journal of Medical Imaging and Health Informatics, 2017, 7, (6), pp. 1385-1390

[31] Sharma, S., Chen, K., and Sheth, A.: 'Toward practical privacypreserving analytics for IoT and cloud-based healthcare systems', IEEE Internet Computing, 2018, 22, (2), pp. 42-51

[32] Dey, N., Ashour, A.S., and Bhatt, C.: 'Internet of things driven connected healthcare': 'Internet of things and big data technologies for next generation healthcare' (Springer, 2017), pp. 3-12

[33] Chen, M., Ma, Y., Li, Y., Wu, D., Zhang, Y., and Youn, C.-H.: 'Wearable 2.0: Enabling human-cloud integration in next generation healthcare systems', IEEE Communications Magazine, 2017, 55, (1), pp. 54-61

[34] Zaman, N., Seliaman, M.E., Hassan, M.F., and Márquez, F.P.G.: 'Handbook of Research on Trends and Future Directions in Big Data and Web Intelligence' (Information Science Reference, 2015. 2015)

[35] Hossain, M.S., and Muhammad, G.: 'Emotion-aware connected healthcare big data towards 5G', IEEE Internet of Things Journal, 2017, 5, (4), pp. 2399-2406

[36] Gill, S.S., Arya, R.C., Wander, G.S., and Buyya, R.: 'Fog-based smart healthcare as a big data and cloud service for heart patients using IoT', in Editor (Ed.) ${ }^{\wedge}$ (Eds.): 'Book Fog-based smart healthcare as a big data and cloud service for heart patients using IoT' (Springer, 2018, edn.), pp. 1376-1383

[37] Manogaran, G., Thota, C., Lopez, D., and Sundarasekar, R.: 'Big data security intelligence for healthcare industry 4.0': 'Cybersecurity for Industry 4.0' (Springer, 2017), pp. 103-126

[38] Rath, M.: 'Big data and iot-allied challenges associated with healthcare applications in smart and automated systems': 'Data Analytics in Medicine: Concepts, Methodologies, Tools, and Applications' (IGI Global, 2020), pp. 1401-1414

[39] Elhoseny, M., Ramírez-González, G., Abu-Elnasr, O.M., Shawkat, S.A., Arunkumar, N., and Farouk, A.: 'Secure medical data transmission model for IoT-based healthcare systems', Ieee Access, 2018, 6, pp. 20596-20608

[40] Malik, V., and Singh, S.: 'Cloud, Big Data \& IoT: Risk Management', in Editor (Ed.)^(Eds.): 'Book Cloud, Big Data \& IoT: Risk Management' (IEEE, 2019, edn.), pp. 258-262

[41] Moustafa, N.: 'A Systemic IoT-Fog-Cloud Architecture for Big-Data Analytics and Cyber Security Systems: A Review of Fog Computing', arXiv preprint arXiv: $1906.01055,2019$

[42] Tariq, N., Asim, M., Al-Obeidat, F., Zubair Farooqi, M., Baker, T., Hammoudeh, M., and Ghafir, I.: 'The security of big data in fog-enabled IoT applications including blockchain: a survey', Sensors, 2019, 19, (8), pp. 1788
[43] Yang, Y., Zheng, X., Guo, W., Liu, X., and Chang, V.: 'Privacypreserving smart IoT-based healthcare big data storage and self-adaptive access control system', Information Sciences, 2019, 479, pp. 567-592

[44] Zaman, N., and Ahmad, M.: 'Towards the Evaluation of Authentication Protocols for Mobile Command and Control Unit in Healthcare', Journal of Medical Imaging and Health Informatics, 2017, 7, (3), pp. 739-742

[45] Balakrishna, S., and Thirumaran, M.: 'Semantic interoperability in IoT and big data for health care: a collaborative approach': 'Handbook of Data Science Approaches for Biomedical Engineering' (Elsevier, 2020), pp. $185-220$

[46] Mishra, K.N., and Chakraborty, C.: 'A Novel Approach Towards Using Big Data and IoT for Improving the Efficiency of m-Health Systems': 'Advanced Computational Intelligence Techniques for Virtual Reality in Healthcare' (Springer, 2020), pp. 123-139

[47] Dineshkumar, P., SenthilKumar, R., Sujatha, K., Ponmagal, R., and Rajavarman, V.: 'Big data analytics of IoT based Health care monitoring system', in Editor (Ed.) $)^{\wedge}(E d s$.$) : 'Book Big data analytics of IoT based$ Health care monitoring system' (IEEE, 2016, edn.), pp. 55-60

[48] Rath, M., and Solanki, V.K.: 'Contribution of IoT and Big Data in Modern Health Care Applications in Smart City', Handbook of IoT and Big Data, 2019, pp. 109-124

[49] Jabbar, S., Ullah, F., Khalid, S., Khan, M., and Han, K.: 'Semantic interoperability in heterogeneous IoT infrastructure for healthcare', Wireless Communications and Mobile Computing, 2017, 2017

[50] Ghosal, P., Das, D., and Das, I.: 'Extensive survey on cloud-based IoThealthcare and security using machine learning', in Editor (Ed.) $)^{\wedge}$ (Eds.): 'Book Extensive survey on cloud-based IoT-healthcare and security using machine learning' (IEEE, 2018, edn.), pp. 1-5

[51] Byrne, S.: 'Remote Medical Monitoring and Cloud-based Internet of Things Healthcare Systems', American Journal of Medical Research, 2019, 6, (2), pp. 19-24

[52] Selvaraj, S., and Sundaravaradhan, S.: 'Challenges and opportunities in IoT healthcare systems: a systematic review', SN Applied Sciences, 2020, 2, (1), pp. 139

[53] Banerjee, A., Chakraborty, C., Kumar, A., and Biswas, D.: 'Emerging trends in IoT and big data analytics for biomedical and health care technologies': 'Handbook of Data Science Approaches for Biomedical Engineering' (Elsevier, 2020), pp. 121-152

[54] Azimi, I., Takalo-Mattila, J., Anzanpour, A., Rahmani, A.M., Soininen, J.-P., and Liljeberg, P.: 'Empowering healthcare iot systems with hierarchical edge-based deep learning', in Editor (Ed.)^(Eds.): 'Book Empowering healthcare iot systems with hierarchical edge-based deep learning' (IEEE, 2018, edn.), pp. 63-68

[55] Cai, H., Xu, B., Jiang, L., and Vasilakos, A.V.: 'IoT-based big data storage systems in cloud computing: perspectives and challenges', IEEE Internet of Things Journal, 2016, 4, (1), pp. 75-87

[56] Tyagi, S., Agarwal, A., and Maheshwari, P.: 'A conceptual framework for IoT-based healthcare system using cloud computing', in Editor (Ed. $)^{\wedge}($ Eds.): 'Book A conceptual framework for IoT-based healthcare system using cloud computing' (IEEE, 2016, edn.), pp. 503-507

[57] Verma, P., Sood, S.K., and Kalra, S.: 'Cloud-centric IoT based student healthcare monitoring framework', Journal of Ambient Intelligence and Humanized Computing, 2018, 9, (5), pp. 1293-1309

[58] Yang, Z., Zhou, Q., Lei, L., Zheng, K., and Xiang, W.: 'An IoT-cloud based wearable ECG monitoring system for smart healthcare', Journal of medical systems, 2016, 40, (12), pp. 286

[59] Ullah, F., Habib, M.A., Farhan, M., Khalid, S., Durrani, M.Y., and Jabbar, S.: 'Semantic interoperability for big-data in heterogeneous IoT infrastructure for healthcare', Sustainable Cities and Society, 2017, 34, pp. $90-96$

[60] Jiang, L., Da Xu, L., Cai, H., Jiang, Z., Bu, F., and Xu, B.: 'An IoToriented data storage framework in cloud computing platform', IEEE Transactions on Industrial Informatics, 2014, 10, (2), pp. 1443-1451

[61] Aazam, M., Khan, I., Alsaffar, A.A., and Huh, E.-N.: 'Cloud of Things: Integrating Internet of Things and cloud computing and the issues involved', in Editor (Ed.)^(Eds.): 'Book Cloud of Things: Integrating Internet of Things and cloud computing and the issues involved' (IEEE, 2014, edn.), pp. 414-419 
[62] Muhammad, G., Rahman, S.M.M., Alelaiwi, A., and Alamri, A.: 'Smart health solution integrating IoT and cloud: A case study of voice pathology monitoring', IEEE Communications Magazine, 2017, 55, (1), pp. 69-73

[63] Plageras, A.P., Stergiou, C., Kokkonis, G., Psannis, K.E., Ishibashi, Y., Kim, B.-G., and Gupta, B.B.: 'Efficient large-scale medical data (ehealth big data) analytics in internet of things', in Editor (Ed.) ${ }^{\wedge}$ (Eds.): 'Book Efficient large-scale medical data (ehealth big data) analytics in internet of things' (IEEE, 2017, edn.), pp. 21-27

[64] Nepal, S., Ranjan, R., and Choo, K.-K.R.: 'Trustworthy processing of healthcare big data in hybrid clouds', IEEE Cloud Computing, 2015, 2, (2), pp. 78-84

[65] Spending on Internet of Things worldwide by vertical in 2015 and 2020. https://bit.ly/2VjWSTx. Acesses on January 2020

[66] Internet of Things (IoT) connected devices installed base worldwide from 2015 to 2025. https://bit.ly/2Vi81TG. Acessed on January 2020

[67] IoT Healthcare in 2020: Companies, devices, use cases and market stats. https://bit.ly/2xG3nXQ. Acessed on January 2020

[68] Projected size of the Internet of Things (IoT) in healthcare market worldwide from 2016 to 2025. https://bit.ly/2XHWcsO. Acessed on January 2020

[69] Number of connected wearable devices worldwide from 2016 to 2022. https://bit.ly/2XTBxSq. Acessed on January 2020

[70] Projected healthcare wearable device shipments worldwide 2015-2021 Published by Statista Research Department, Sep 15, 2016

[71] Forecast unit shipments of wearable devices worldwide from 2017 to 2019 and in 2022 (in million units), by category https://bit.ly/2z7QRk5. Accessed on January 2020

[72] Number of connected wearable devices worldwide by region 2015-2022 Published by Statista Research Department, Feb 19, 2020

[73] Gartner Forecasts Worldwide Public Cloud Revenue to Grow 17.5 Percent in 2019. https://gtnr.it/2wOZOhu. Acessed On Februarry 2020

[74] Schmidt, Cameron, and Jake Ellis. "Manufacturing." In Enterprise Cloud Computing for Non-Engineers, pp. 77-86. Auerbach Publications, 2018.

[75] McGrath, Michael J., John Kennedy, Jens Jensen, Shirley Crompton, Anna Queralt, Jasenka Dizdarevic, Sašo Stanovnik et al. "D2. 3 Tracking Scientific, Technology and Business Trends (Version 3)."

[76] Global Healthcare Cloud Computing Market Predicted to Grow at a CAGR of Over 21\% Through 2021: Technavio. https://bwnews.pr/3csT485. Acessed on Feburary 2020

[77] Big Data cloud the Internet of things: what the IoT platform and why they are needed. https://bit.ly/2ytIEXq. Acessed on Feburary 2020

[78] Big data market size revenue forecast worldwide from 2011-2027 https://bit.ly/3eB4Cbe. Acessed on Feburary 2020

[79] https://wikibon.com/2016-2026-worldwide-big-data-market-forecast/

[80] Dash, S., Shakyawar, S.K., Sharma, M., and Kaushik, S.: 'Big data in healthcare: management, analysis and future prospects', Journal of Big Data, 2019, 6, (1), pp. 54
[81] Global digital health market from 2015 to 2020, by major segment. https://bit.ly/2VCJR6s. Acessed on Feburary 2020

[82] Big Data a \$4.7 Billion opportunity in the healthcare and pharmaceutical industry, says SNS Telecom \& IT https://bit.ly/2VjNuPT. Acessed on Feburary 2020

[83] Evans Data Corporation Global Development Survey, Volume 1. https://bit.ly/2wUfVdQ. Acessed on Feburary 2020

[84] Darwish, A., Hassanien, A.E., Elhoseny, M., Sangaiah, A.K., and Muhammad, K.: 'The impact of the hybrid platform of internet of things and cloud computing on healthcare systems: opportunities, challenges, and open problems', Journal of Ambient Intelligence and Humanized Computing, 2019, 10, (10), pp. 4151-4166

[85] Dang, L.M., Piran, M., Han, D., Min, K., and Moon, H.: 'A survey on internet of things and cloud computing for healthcare', Electronics, 2019, 8, (7), pp. 768

[86] Mohapatra, S., and Parija, S.: 'A Brief Understanding of IOT Health Care Service Model Over Remotely Cloud Connected Environment': 'Advances in Intelligent Computing and Communication' (Springer, 2020), pp. 46-51

[87] Aceto, G., Persico, V., and Pescapé, A.: 'Industry 4.0 and Health: Internet of Things, Big Data, and Cloud Computing for Healthcare 4.0', Journal of Industrial Information Integration, 2020, pp. 100129

[88] Kharbouch, A., Naitmalek, Y., Elkhoukhi, H., Bakhouya, M., De Florio, V., El Ouadghiri, M.D., Latre, S., and Blondia, C.: 'IoT and Big Data Technologies for Monitoring and Processing Real-Time Healthcare Data', International Journal of Distributed Systems and Technologies (IJDST), 2019, 10, (4), pp. 17-30

[89] Chanchaichujit, J., Tan, A., Meng, F., and Eaimkhong, S.: 'Internet of Things (IoT) and Big Data Analytics in Healthcare': 'Healthcare 4.0' (Springer, 2019), pp. 17-36

[90] Bansal, M., and Gandhi, B.: 'IoT \& Big Data in Smart Healthcare (ECG Monitoring)', in Editor (Ed.)^(Eds.): 'Book IoT \& Big Data in Smart Healthcare (ECG Monitoring)' (IEEE, 2019, edn.), pp. 390-396

[91] Almasi, S., and Pratx, G.: 'Cloud computing for big data', Big Data in Radiation Oncology, 2019, pp. 61-78

[92] Rajabion, L., Shaltooki, A.A., Taghikhah, M., Ghasemi, A., and Badfar, A.: 'Healthcare big data processing mechanisms: the role of cloud computing', International Journal of Information Management, 2019, 49, pp. 271-289

[93] Karaca, Y., Moonis, M., Zhang, Y.-D., and Gezgez, C.: 'Mobile cloud computing based stroke healthcare system', International Journal of Information Management, 2019, 45, pp. 250-261

[94] Smys, S., and Raj, J.S.: 'Internet of things and big data analytics for health care with cloud computing', Journal of Information Technology, 2019, 1, (01), pp. 9-18

[95] Sudheep, K., and Joseph, S.: 'Review on Securing Medical Big Data in Healthcare Cloud', in Editor $(E d .)^{\wedge}(E d s$.$) : 'Book Review on Securing$ Medical Big Data in Healthcare Cloud' (IEEE, 2019, edn.), pp. 212-215 